\title{
TREATMENT WITH GLP-1-RAS IN TYPE 2 DIABETES AND OBESITY PATIENTS
}

Romero Porcel J. A.; Cuellar Lloclla E.A.; Cantudo Cuenca M. R.; Martinez de Pinillos Gordillo G.; García Pérez F.; Fernández Peña J.I.; García de Quiros J.M.; Fernandez Lopez J.I.; Cozar León M.V.

INTRODUCTION: Assessing the effect of GLP 1 receptor agonist on metabolic control and weight loss in obesity and type 2 diabetes patients.

\section{DESCRIPTION OF METHODS}

* A retrospective descriptive study involving type 2 diabetes patients and $\mathrm{BMI}>30 \mathrm{~kg} / \mathrm{m} 2$, who started treatment with GLP-1-RAs during the years 2012 to 2014

* Variables analyzed: weight and HbA1c at the begging, six months, one and two years; Regimen at baseline and after GLP-1-RAs; Incidence of withdrawal of treatment.

* Student's t-test for the comparison of two means were used

\section{RESULTS}

\begin{tabular}{|c|c|}
\hline MEN & $73(58.4 \%)$ \\
\hline WOMEN & $52(41.6 \%)$ \\
\hline TOTAL & 125 \\
\hline MEAN AGE & 55,4 \\
\hline
\end{tabular}

GLP-1-RAs

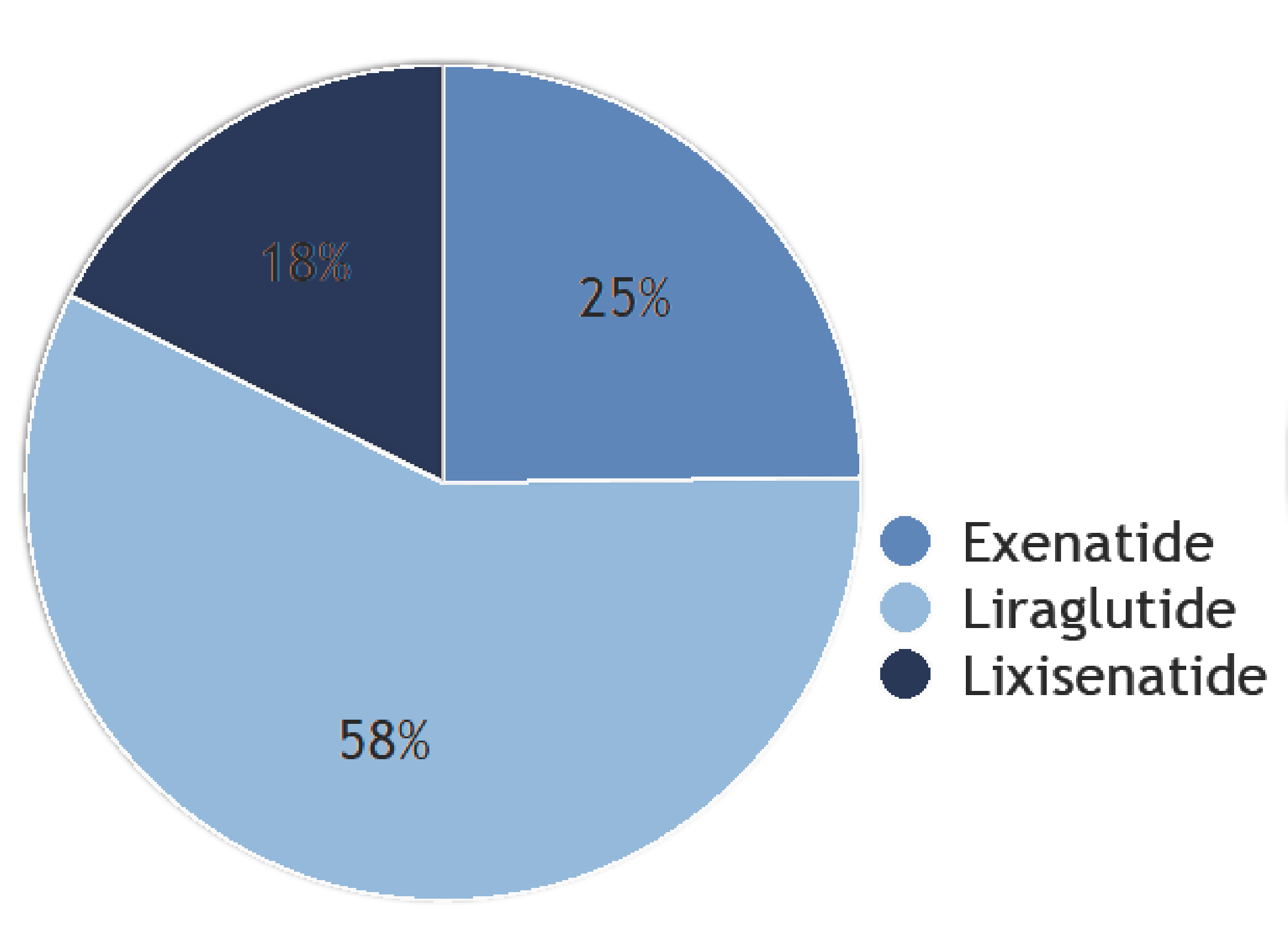

Therapy discontinued

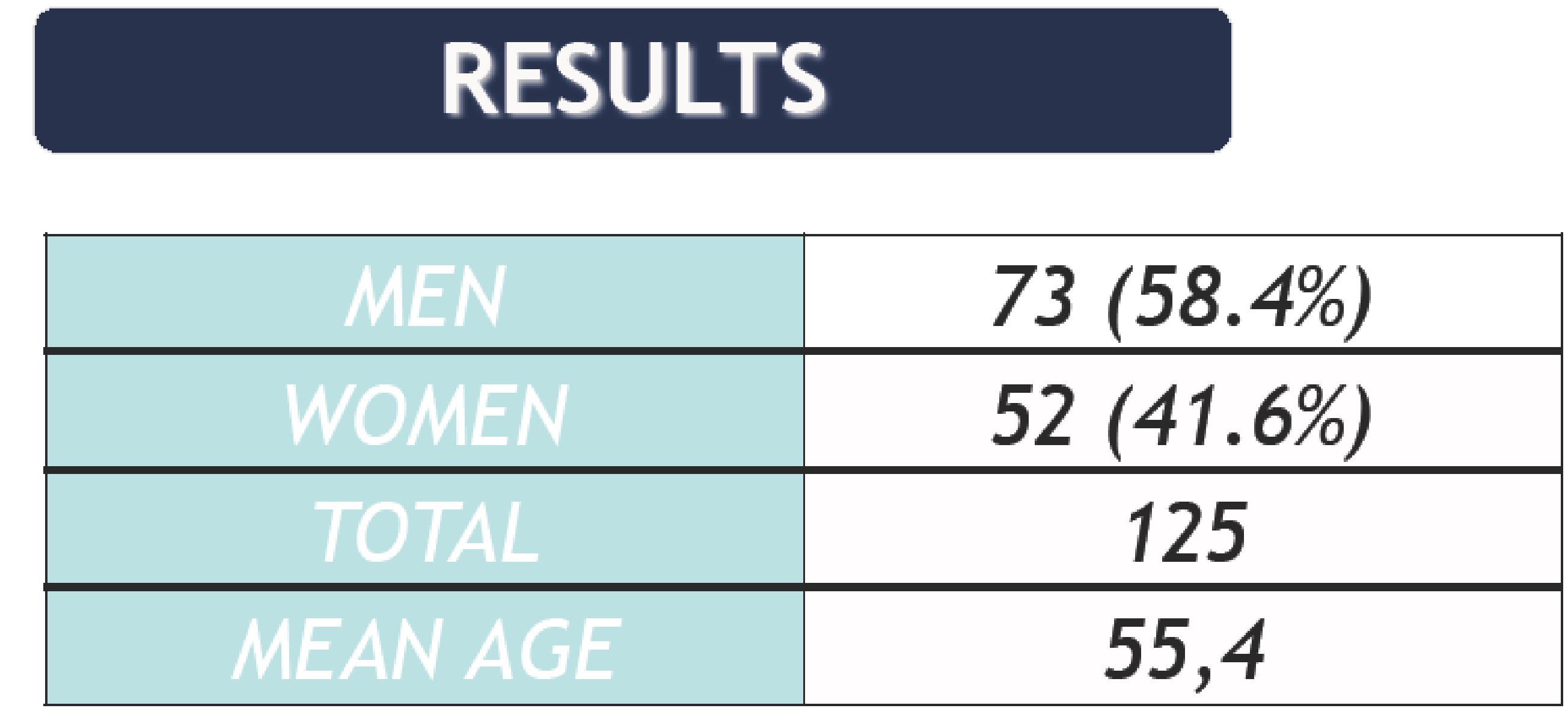

HbA1c Evolution (\%)

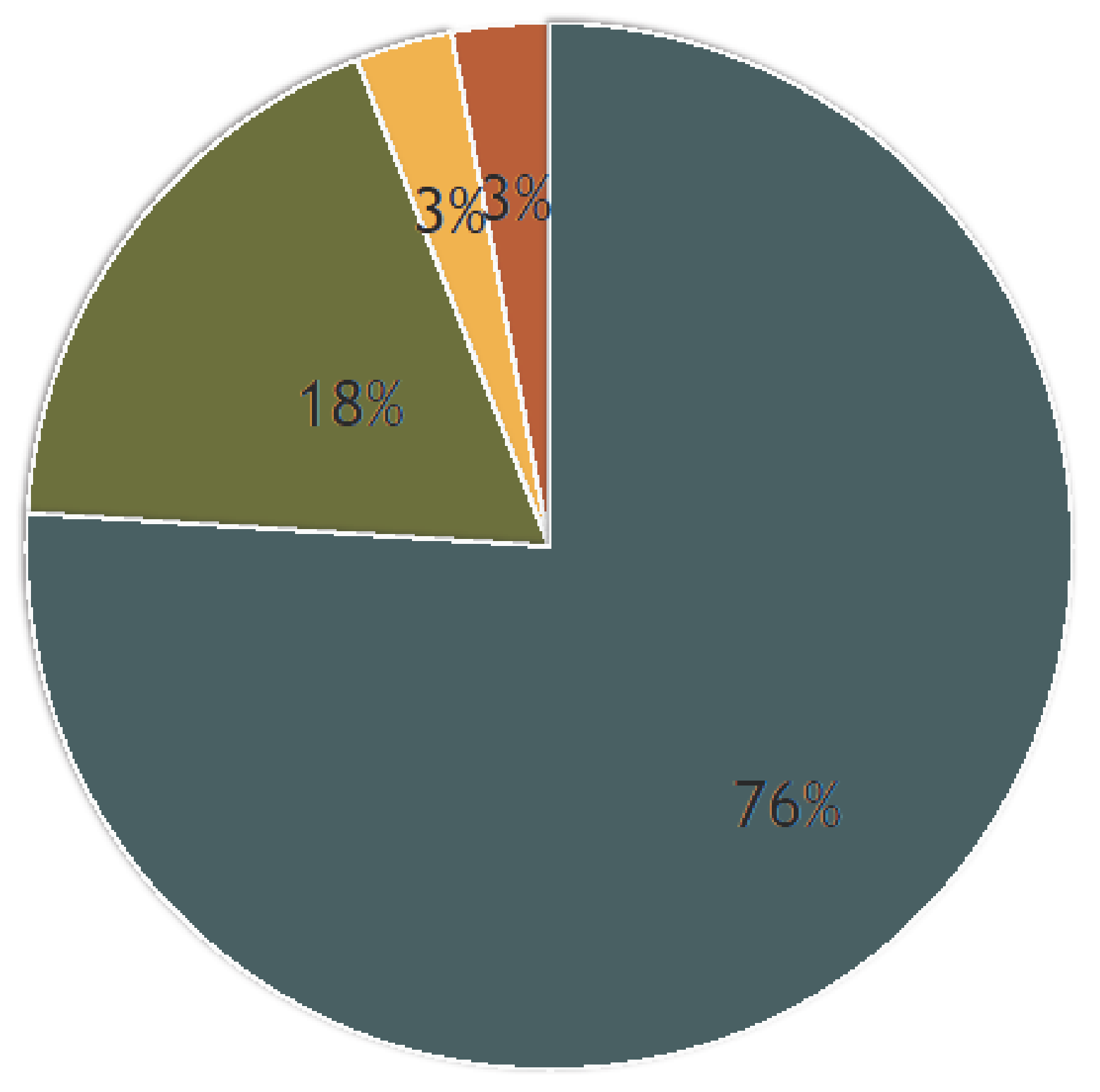

Lack of response to treatment Gastrointestinal intolerance Patient choice Others

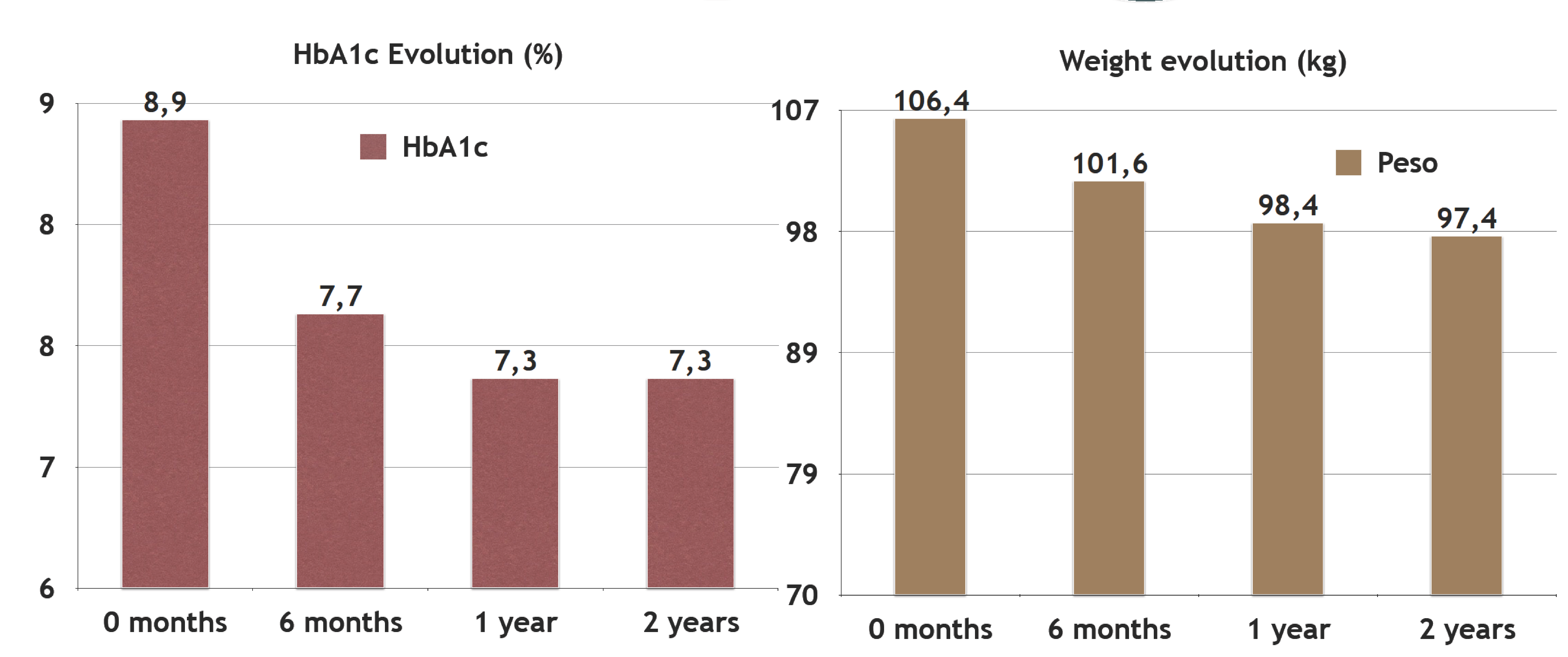

* The difference in $\mathrm{HbA1c}$ and weight at baseline and 6 months, 1 year and 2 years follow-up statistically significant $(p<0.001)$, not statistically significant difference the first and second years of therapy * 56.8\% were treated with insulin at start. After addition GLP-1-RAs insulin treatment was finished by $9.9 \%(45.2 \%$ basal bolus therapy who changed baseline insuline and OADs).

\section{CONCLUSIONS}

* GLP-1 agonist inclusion in type 2 diabetes therapy improves glycemic blood control and loss weight.

* Improvement already 6 months and holding the first and second year.

* The treatment contributed to simplify the therapeutic regimen in many patients insulinized, which is reflected in that almost half of those doing intensive treatment could stop the rapid insulin without prejudice to its metabolic control.

* However, as reflected in the literature, we found a significant number of patients that the treatment provided no improvement, this lack of response so early been observed. 